\title{
Errata: Resolution in the ApoTome and the confocal laser scanning microscope: comparison
}

\author{
Arwed Weigel, ${ }^{a, b}$ Detlev Schild, ${ }^{a, b}$ and André Zeug ${ }^{a, b}$ \\ a University of Göttingen, Department of Neurophysiology and Cellular Biophysics, Humboldtallee 23, \\ 37073 Göttingen, Germany \\ beutsche Forschungsgemeinschaft-Research Center for the Molecular Physiology of the Brain (FZT 103), \\ Göttingen, Germany
}

[DOI: $10.1117 / 1.3585832]$

This article [J. Biomed. Opt. 14, 014022 (2009)] was originally published online on 25 February 2009. The authors wish to add an acknowledgment of a grant received.

On p. 8, the following sentence has been added to the Acknowledgments: "We also acknowledge financial support by the German Ministry for Education and Research (BMBF) via the Bernstein Center for Computational Neuroscience (BCCN) Göttingen under Grant No. 01GQ0432."

The article was corrected online on 18 April 2011. 